\title{
AFRO-PATRIMÔNIO NO PLURAL: A MISTURA NO CANDOMBLÉ COMO VALOR EXCEPCIONAL
}

\section{AFRO-HERITAGE IN PLURAL: \\ THE MIXTURE IN CANDOMBLÉ AS OUTSTANDING VALUE}

\section{Stefania Capone}

stefania.capone@ehess.fr

Doutora em Etnologia pela Universidade de Paris X-Nanterre.

Diretora de pesquisa de primeira classe no Centro Nacional de Pesquisa Científica da França (CNRS)e membro do Centro de Estudos em Ciências Sociais da Religião (CéSor) da EHESS, Paris.

ORCID: https://orcid.org/0000-0001-7374-3081

\section{Mariana Ramos de Morais}

marianaramosdemorais@gmail.com

Doutora em Ciências Sociais pela PUC Minas.

Pesquisadora associada doCentro de Estudos em Ciências Sociais da Religião (CéSor) da EHESS, Paris.

ORCID: https://orcid.org/0000-0002-1604-2366

\section{RESUMO}

Este artigo propõe uma reflexão sobre o processo de patrimonialização das religiões afro-brasileiras, com foco especial no candomblé. Desde pelo menos a década de 1950, essa religião, quando entendida como um dos elementos que compõem a cultura popular, sobretudo os vinculados aos afrodescendentes, tem sido valorizada na construção de uma ideia de nação brasileira. No entanto, tal valorização não ocorre sem conflitos e negociações, evidenciados no tombamento de alguns terreiros de candomblé pelo Instituto do Patrimônio Histórico e Artístico Nacional (IPHAN). Dentre os poucos terreiros alçados a patrimônio nacional, os de matriz jeje-nagô são predominantes. Associações de adeptos de candomblé que reivindicam uma herança cultural banta questionam essa hegemonia. Para tanto, esforçam-se em cravar à sua representação uma raiz africana "autêntica", lançando-se na busca de uma África banta, ou tentam fazer da "mistura" sua marca distintiva.

Palavras-chave: afro-patrimônio; candomblé; mistura.

\section{ABSTRACT}

This article aims to analyze the process of heritagization of the Afro-Brazilian religions, focusing mainly in Candomblé. Since the 1950's, this religion, considered as one of the elements composing the popular culture, especially the ones linked to the Afro-descendants, has been included in the construction of the Brazilian nation. However, such inclusion does not take place without conflicts and compromises that can be seen clearly in the selection of some Candomblé terreiros (cult houses) by the National Institute for Historic and Artistic Herita- 
ge (IPHAN). Among the few houses declared national heritage, the terreiros of jeje-nagô origin are predominant. However, Candomblé followers associations claiming for a Bantu cultural heritage question this hegemony. Hence, they make an effort to embed an "authentic" African root to their representations, casting themselves in the quest for a Bantu Africa, or they try to valorize "mixture" as their own distinctive brand.

Keywords: afro-heritage; candomblé; mixture.

Logo na abertura do seu "O candomblé da Bahia", publicado no final dos anos 1950', Roger Bastide justifica sua escolha pelo estudo do "rito nagô” dentre as distintas modalidades de candomblé, ao sentenciar:

[...] a influência dos iorubás domina sem contestação o conjunto de seitas africanas, impondo seus deuses, a estrutura de suas cerimônias e sua metafísica aos daomeanos, aos bantos. É porém evidente que os candomblés nagô, queto e ijexá são os mais puros de todos, e só eles serão estudados aqui (BASTIDE, 2001 [1958], p. 29).

No trecho acima, bem conhecido e também citado por quem se envereda pelos estudos das religiões afro-brasileiras, Bastide não apenas justifica sua escolha como também hierarquiza as modalidades de candomblé. Essa hierarquização é herdada de seus antecessores - iniciando com Nina Rodrigues e, na sequência, Arthur Ramos e Édison Carneiro, para mencionar os principais pesquisadores brasileiros sobre essa temática nas primeiras décadas do século XX. Ela também reverbera em trabalhos posteriores aos seus que insistem em creditar aos candomblés nagôs, ou seja, aos terreiros de matriz iorubá, superioridade, especialmente, frente aos bantos.

Nesse último caso, a suposta inferioridade não se restringiria às modalidades de candomblé inspiradas em diferentes povos denominados bantos, pois seria extensiva a outras práticas religiosas surgidas no Brasil a partir do legado desses povos, como a umbanda. Para aqueles que coadunam com as formulações bastidianas, as religiões advindas dos bantos seriam “degeneradas", já que mais abertas a influências externas, enquanto que o candomblé nagô teria sido capaz de preservar em terras brasileiras a "pureza" ritual africana.

A classificação das religiões vinculadas aos bantos como "degeneradas" e as advindas dos iorubás como "puras" é uma constante nos estudos afro-brasileiros, ainda que, a partir dos anos 1970, estudos antropológicos tenham apresentado uma leitura crítica sobre como essa ideia foi construída discursivamente (MAGGIE, 1977; DANTAS, 1988; CAPONE, 1996, 1999, 2018). Sacerdotes e sacerdotisas nagôs, juntamente com intelectuais, pesquisadores e artistas, compõem a engrenagem propulsora (e mesmo mantenedora) dos mecanismos que a colocaram em ação. Trata-se, portanto, de uma construção coletiva que evidencia os conflitos e as negociações no campo afro-religioso, constituído em 
permanente descolamento transatlântico, tendo o Brasil como um dos seus principais portos.

Neste artigo, a referida ideia também se faz presente. Não se intenta, contudo, refutá-la, tão pouco reiterá-la. Ela surge à medida que refletimos sobre como as religiões afro-brasileiras, materializadas em seus locais de culto, são alçadas a patrimônio cultural no Brasil. Na lista ainda diminuta - dos terreiros tombados pelo Instituto do Patrimônio Histórico e Artístico Nacional (IPHAN), os nagôs são proeminentes. Dentre os onze terreiros patrimonializados pelo IPHAN, sete têm raízes iorubás, dois são jejes e, os outros dois, bantos. Seria uma consolidação da "pureza" nagô?

Os números acima indicam uma resposta afirmativa. No entanto, a cena patrimonial não é estanque. Nela repercutem as dinâmicas dos diferentes grupos que disputam o reconhecimento concedido via patrimonialização. Mais do que uma análise ligeira de números absolutos, nossa proposta aqui é percorrer o período compreendido entre o primeiro tombamento, em 1984, e os últimos, em 2018, pensando sobre os critérios e os argumentos que fundamentaram as escolhas dos terreiros tornados monumentos. Nesse percurso, atentamos para a forma como as disputas próprias do campo afro-religioso incidem na cena patrimonial.

A ideia das religiões afro-brasileiras como patrimônio é elaborada a partir de um movimento empreendido por diferentes agentes, tais como gestores do patrimônio, sacerdotes e sacerdotisas, intelectuais, artistas, políticos e militantes negros. Eles estão em constante diálogo com outros agentes que atuam no contexto que se convencionou chamar de "Atlântico Negro". Ora por meios distintos, ora convergindo agendas, esses agentes buscam tornaras religiões afro-brasileiras - e os sítios sagrados a elas vinculados - em uma encarnação de uma memória negra, estreitamente ligada aos traumas da escravidão.

Nesse sentido, a reflexão que propomos está ancorada em uma confluência de discursos que surgem na atual cena em que as religiões afro-brasileiras protagonizam um importante papel por dois motivos em especial. Primeiramente, pelo fato de elas amalgamarem elementos que hoje compõem o vasto espectro cultural afro-brasileiro. E também pelo fato deseus praticantes, ao irem em busca de suas supostas raízes africanas, perfazerem as antigas rotas dos escravos em seus traslados transnacionais, sejam eles míticos ou reais, além de agregarem novas rotas extrapolando o ir e vir ao continente africano. Essa busca, contudo, não é mais empreendida apenas por aqueles alinhados à modalidade nagô, mas também pelos praticantes do candomblé nomeado angola em tempos passados e, hoje, reivindicado como "bantu", uma denominação que reforça sua ligação com a África.

A distinção entre bantos e nagôs, conforme já mencionamos nesta introdução, consta também do processo de patrimonialização dos terreiros pelo IPHAN². Os termos "puros" e "degenerados", porém, são 
transladados aos poucos para os termos congêneres: "tradicionais" e "misturados". Nessa tradução, o termo "puro", antes restrito à modalidade nagô, quando transposto para o termo "tradicional", passa a abarcar outras modalidades que também se afirmam como detentoras de uma tradição africana. E o peso negativo do que era tratado como "degenerado" ganha vigor por ser "misturado" no amplo espectro que emerge com o discurso valorativo da dita diversidade cultural. Ao traçarmos o percurso da patrimonialização das religiões afro-brasileiras estaremos, assim, apontando se e em que medida a constituição desse afro-patrimônio se conjuga no "plural".

\section{AFRO-PATRIMÔNIO}

Adotamos o termo "afro-patrimônio" para nos referirmos aos bens culturais de matriz africana -tais como a capoeira, o jongo, o tambor de crioula, o samba de roda, os quilombos e também os terreiros -incorporados à política patrimonial brasileira (CAPONE; MORAIS, 2015). A emergência dos "afro-patrimônios" foi o resultado de um conjunto de fatores. A reorganização do movimento negro em sua luta pela igualdade racial e contra o racismo, nos anos 1970, foi um deles. Outros dois fatores foram as celebrações pelo centenário da abolição da escravatura e a promulgação da chamada Constituição Cidadã, ambos em 1988. Vale citar também o alinhamento do governo brasileiro às políticas propostas pela Unesco pautadas no paradigma multicultural. Além de outras questões globais que também incidiram na reconfiguração das identidades culturais de matriz africana.

Lembramos que, apesar de a herança cultural dos africanos e seus descendentes ser referenciada na ideia de nação brasileira difundida nos anos 1930, quando da instituição da política patrimonial no âmbito nacional, os bens culturais afro-brasileiros não ganhavam destaque entre aqueles alçados a patrimônio. Somente a partir dos anos 1980 que esses bens culturais foram, paulatinamente, sendo integrados ao patrimônio nacional, fato intensificado no início dos anos 2000. Interessante notar que, nesse contexto, a preservação dos bens culturais afro-brasileiros passa a ser reivindicada não apenas como um reconhecimento, mas como uma forma de reparação pelos danos sofridos pela população negra devido à escravidão.

A patrimonialização pode, assim, ser uma forma de dar visibilidade a grupos antes a margem das políticas públicas ou que não tinham reconhecidas suas contribuições na formação sociocultural -e também política e econômica - da nação, ou seja, a patrimonialização pode ser um instrumento de inclusão social. A própria Constituição Federal de 1988, ao afirmar o caráter pluriétnico da sociedade brasileira e ao estabelecer como dever do Estado zelar pelo patrimônio culturalrelativo 
aos grupos sociais formadores da nação, em especial neste caso os afro-brasileiros, é um amparo legal que assegura, ao menos na letra, o acesso desses grupos aos seus direitos fundamentais. No entanto, a patrimonialização também hierarquiza, cria modelos ideais, define regras para escolher o que deve e o que não deve ser reconhecido como patrimônio cultural. Ao patrimonializar os bens culturais, o Estado também exclui aqueles bens que não se adequam a um padrão estabelecido ou que não apresentam um "valor excepcional".

Possuir um valor que se distingue pela excepcionalidade é uma condição expressa desde 1937, quando da publicação do Decreto-Lei 25 que constitui a base legal para a organização da proteção do patrimônio cultural brasileiro. Conforme a referida legislação, que segue em vigor, um bem móvel ou imóvel pode tornar-se um patrimônio nacional uma vez que sua conservação seja de interesse público por estar vinculado a fatos memoráveis da história brasileira ou por seu "excepcional valor arqueológico ou etnográfico, bibliográfico ou artístico” (BRASIL, 1937). É preciso, assim, que o bem cultural se distinga por sua excelência, por apresentar características fora do comum, por ser uma exceção.

Por quase 50 anos, às religiões afro-brasileiras não foi conferida tal condição. Quando da instituição da política patrimonial brasileira, foram privilegiados, especialmente, as igrejas católicas e os casarios com a "marca" do barroco. Às religiões afro-brasileiras coube uma vaga lembrança da forma como eram tratadas no período. Juntamente com os primeiros patrimônios brasileiros, foi registrada em 1938 a Coleção Museu da Magia Negra, composta de objetos sagrados apreendidos em ações policiais nas décadas de 1920 e de 1930 no Rio de Janeiro. Porém, tal coleção somente passou a ser listada entre os bens patrimonializados nos anos 1980, após o tombamento do terreiro da Casa Branca, em Salvador (BA), considerado um dos berços do candomblé nagô na Bahia (CORREAA, 2005).

O tombamento da Casa Branca foi aprovado em 1984, durante uma conturbada reunião do Conselho Consultivo do IPHAN, que ainda operava sob os ditames que moldavam de pedra e cal os patrimônios no Brasil. A sua patrimonialização representava uma ruptura com o modelo até então vigente, como apontou Gilberto Velho, relator do processo de tombamento desse terreiro (VELHO, 2006). Um modelo que, dos anos 1970 para os 1980, passava a ser contestado dentro e fora do IPHAN, devido a uma mudança paradigmática que incidia diretamente na concepção do patrimônio cultural: a eclosão do multiculturalismo.

Nesse mesmo período, ou seja, na passagem da década de 1970 para a de 1980, era crescente a afirmação do candomblé como modelo de ortodoxia afrorreligiosa, em especial na sua modalidade nagô fundada na Bahia. Essa afirmação baseava-se, em parte, nas proposições bastidianas. Essas proposições foram reelaboradas nos escritos militantes de Abdias do Nascimento (1980), que ecoavam na atuação do nascente Movimen- 
to Negro Unificado bem como de outras entidades negras criadas no fim da década de 1970. Mas também encontravam ressonância na ação de sacerdotisas e sacerdotes de candomblé que travavam uma luta contra o sincretismo afro-católico e empreendiam uma busca pela África ao forjarem novos laços com o continente matriz. Laços esses nem tão novos assim para os precursores do movimento de reafricanização do candomblé nagô, já que compreendido como uma continuidade das comunicações transatlânticas advindas dos tempos coloniais (CAPONE, 1999). O próprio terreiro da Casa Branca tem seu mito fundador assentado nessas circulações transatlânticas. Não por acaso foi ele o escolhido para inaugurar a lista dos terreiros inscritos como patrimônio nacional.

Após o tombamento da Casa Branca, somente em 1999 outro terreiro de candomblé foi alçado a patrimônio nacional: o Axé Opô Afonjá, também em Salvador (BA) e vinculado à modalidade nagô. Desde então, outros nove terreiros passaram a figurar entre os patrimônios nacionais: Casa das Minas, em São Luís (MA); Gantois, em Salvador (BA); Alaketo, em Salvador (BA); Bate Folha, em Salvador (BA); Ilê Axé Oxumaré, em Salvador (BA); Roça do Ventura, em Cachoeira (BA); Omo Ilê Agbôulá, em Itaparica (BA); Tumba Junsara, em Salvador (BA); e Sítio Pai Adão, em Recife (PE).

Dos onze terreiros patrimonializados no âmbito federal até 2018, sete vinculam-se à tradição nagô, dois à tradição jeje e outros dois à tradição banta. Desses, oito estão na Bahia, estado tido como a meca do candomblé, embora essa religião afro-brasileira esteja difundida, hoje, por todo o território brasileiro. Além disso, essa pequena amostra exclui a pluralidade constitutiva das religiões afro-brasileiras, uma vez que há uma proeminência do candomblé baiano, sobretudo de tradição nagô, entre os terreiros patrimonializados. Dentre as variadas denominações que se situam sob o termo "religiões afro-brasileiras" um terreiro de tambor de mina (Casa das Minas), um de culto aos Egunguns (Omo Ilê Agbôulá) e um de xangô (Sítio do Pai Adão) se juntam aos de candomblé na lista dos patrimônios nacionais, entre os quais constam, como mencionado, somente dois terreiros de tradição banta. Ainda sobre o conjunto desses afro-patrimônios, vale informar que tanto o terreiro de xangô quanto o de culto aos Egungunsreivindicam uma origem iorubá.

A hegemonia nagô exaltada na literatura acerca das religiões afro-brasileiras reverbera na representação das religiões afro-brasileiras como patrimônio nacional, observando-se duas dinâmicas: uma geográfica e também política - a centralidade da Bahia nessa construção patrimonial - e outra cultural - a centralidade da tradição nagô/iorubá. No que diz respeito às religiões afro-brasileiras, a política nacional de patrimônio parece assim encontrar-se "em conserva" (MORAIS, 2015; 2018), relembrando aqui um termo cunhado por Roger Bastide (1996) para se referir à capacidade de alguns terreiros de candomblé nagô da Bahia em preservar a prática religiosa seguindo moldes africanos. Esse 
estado quase estático começou, porém, a ser rompido diante da crescente reivindicação de praticantes do candomblé de tradição banta para serem incluídos em ações vinculadas não apenas ao patrimônio cultural como a uma gama de políticas públicas criadas no Brasil com a chancela da diversidade cultural.

\section{CANDOMBLÉ BANTU}

A partir dos anos 1990, praticantes do candomblé de tradição banta passaram a se organizar visando a afirmação dessa modalidade de culto frente à proeminência nagô. Um dos marcos dessa mobilização foi um encontro de candomblecistas vinculados à tradição banta, ocorrido em São Paulo, em 1994 (PREVITALLI, 2012). Logo no ano seguinte, em 1995, foi fundada a Confederação das Tradições e Culturas Bantu no Brasil (Cobantu), cujo presidente foi Tata Tauá. Ele mantinha vínculos com o terreiro Bate Folha, em Salvador, um dos mais antigos terreiros de candomblé angola na Bahia e tombado como patrimônio nacional em 2003. Em 1998, foi fundado o Centro de Estudo e Pesquisa da Tradição de Origem Bantu (Ceptob) por Tata Laércio, pai-de-santo do terreiro Manso KilembekwetaLembaFuranam, na Bahia.

Nos anos 2000, outras entidades foram criadas. A Associação Cultural de Preservação do Patrimônio Bantu (Acbantu) foi fundada na Bahia, em 2000. O Monabantu, Movimento Nação Bantu, surgiu em 2004, tendo uma sede em São Paulo e outra em Minas Gerais. Ainda na primeira década dos anos 2000 foi criada a Associação de Cultura Banto do Litoral Norte Paulista (Acubalin), coordenada por Tata Kajalacy. E, desde 2003, acontece o Encontro de Tradições Bantas, o Ecobantu, cujo organizador é Tata Katuvanjesi. Ele também é presidente do Instituto Latino Americano de Tradições Afro Bantu (Ilabantu), criado em $2007^{3}$.

Em um dos caminhos escolhidos no intuito de afirmar o candomblé banto, seus sacerdotes e suas sacerdotisas esforçam-se por cravar à sua representação uma raiz africana "autêntica", imbuída da ideia de "pureza", questionada no campo acadêmico, mas que ainda é fonte de legitimação no campo religioso. Para tanto, lançam-se na busca de uma África banta. Em vez desses sacerdotes e sacerdotisas partirem do Brasil para países como Benim e Nigéria, referências para o candomblé nagô, eles partem para Angola, país que abriga parte do território ocupado pelos povos reunidos sob o termo classificatório "banto". Os sacerdotes Tata Kajalacy e Tata Katuvanjesi, por exemplo, já estiveram nesse país, sendo que Tata Katuvanjesi mantem um contato continuado recebendo, inclusive, representantes de comunidades tradicionais africanas em seu terreiro. Junto com Tauá, Katuvanjesi é apontado como um dos sacerdotes paulistas que tem buscado "redescobrir a África contida na nação angola” (PREVITALLI, 2012, p. 46). Em uma entrevista concedida em 
15 de novembro de 2018, Tata Katuvanjesi se definia como sendo "o rei da reafricanização do candomblé de angola"4.

Observando a busca que tem sido empreendida pelos praticantes do candomblé de tradição banta pelas supostas raízes africanas, fica evidente a similitude com o movimento de reafricanização do candomblé de tradição nagô. Vale lembrar que esse movimento constitui uma busca continuada pela África a partir da articulação de praticantes do candomblé com intelectuais, acadêmicos e políticos. Um movimento que tem contribuído para reformular, desde os anos 1980, o campo religioso afro-brasileiro e que apresenta variações regionais. No Sudeste brasileiro, por exemplo, esse movimento ocorre principalmente por meio do aprendizado da língua iorubá e de cursos de adivinhação (sobretudo através o oráculo de Ifá), assim como pela incorporação de outras tradições religiosas afro-americanas, como a santería ou Ocha/Ifá afro-cubana. Ao passo que, na região Nordeste, o debate sobre a dessincretização do candomblé tem se destacado (CAPONE, 2016).

Mas, no caso do candomblé de tradição banta, essa distinção regional parece ter um impacto menor no movimento de reafricanização, uma vez que ao longo de todo o século XX tem sido reiterada a ideia de que essa modalidade de culto não é dotada da mesma "pureza" atribuída aos nagôs, nem mesmo em Salvador. Dessa forma, não bastaria aos terreiros bantos da Bahia eliminar de suas práticas todos os elementos que remetem ao sincretismo afro-católico, como o que é defendido pelo movimento contra o sincretismo nas casas matrizes do candomblé nagô. Faz-se então necessário o aprendizado das línguas, como umbundo, quicongo e quimbundo, e a incorporação de outras tradições religiosas encontradas na África. Essas tradições "bantas" são muitas vezes redescobertas através dos livros - que vão desde a literatura produzida pelos missionários dos séculos XVIII e XIX às etnografias do início do século XX. Mas também por meio de viagens ao continente africano empreendidas por sacerdotes, que procuram por comunidades onde as tradições ainda estariam "preservadas", como no caso das viagens de Tata Kajalacy e Tata Katuvanjesi.

A primeira viagem de Tata Katuvanjesi à Angola aconteceu em 2009 e durou 15 dias. Em Cambinda, no extremo norte do país, ele foi convidado a passar por um processo de "reiniciação":

Ali foi feito um ritual de sacralização de animais no meu corpo, depois eu não me recordo de muita coisa porque eu fui tomado pela divindade, como diz o baiano, eu espiritei. E então, depois de tudo isso, eu fiquei três dias dentro daquele quarto escuro. O chão, as paredes de barro... Uma coisa bem diferente da nossa aqui, no Brasil. E aí ele [o iniciador] disse que eu estava preparado, inclusive usou essa expressão 'Você tem que estar preparado espiritualmente para vencer grandes desafios que a vida lhe impõe. E aí ele me preparou para a viagem, disse que eu estava pronto para atravessar o oceano Atlântico e vir embora para minha kuabata, ou seja, aldeia. ${ }^{5}$ 
Outras viagens seguiram. Foram sete desde 2009. Em 2015, Tata Katunvajesi foi admitido na corte do Bailundo, "o reino do povo umbundu", como sobá (autoridade tradicional) da diáspora, depois de passar por rituais conduzidos pelos nganga(sacerdotes) do rei, Armindo Francisco Kalupeteka (Ekwikwi V). Tata Katuvanjesi explica assim a sua viagem de retorno à tradição banta:

Eles reconheceram o trabalho e a preocupação e acho que ficaram impressionados com essa nossa vontade de melhor aproximar as raízes, as origens. O rei disse que aquilo que ele tava fazendo, era uma determinação dos ancestrais. Que eu era um filho que voltava. [...] São experiências que eu passei que eu digo 'Meu Zambi, eu não estou em terras diferentes. Eu fui apenas sequestrado daqui.'Então tudo que eu vivi até hoje com essa viagem, essa travessia do Atlântico, é na realidade, uma contribuição que me ajudou a repensar o candomblé. ${ }^{6}$

O movimento de reafricanização - seja ele capitaneado por praticantes do candomblé de tradição banta ou de tradição nagô - busca, antes de tudo, a legitimação da prática religiosa em um campo marcado por disputas e conflitos desde a sua instituição. Assim, uma das principais diferenças entre os movimentos empreendidos por cada uma dessas modalidades de culto é de cunho temporal.

De fato, o movimento de reafricanização das casas de candomblé nagô eclode nos anos 1980, enquanto o movimento banto se estrutura, principalmente, entre a segunda metade da década de 1990 e o início dos anos 2000. Essa diferença temporal está diretamente relacionada à maneira como esses dois grupos apresentam sua agenda e buscam articulá-la politicamente. No caso da reafricanização das casas nagôs, as políticas públicas marcadas pelo multiculturalismo ainda estavam sendo pensadas quando há uma intensificação desse movimento. No caso do movimento banto, essas políticas já estavam sendo implementadas. Políticas essas que são implementadas no Brasil, mas seguem preceitos de organismos internacionais, como a Unesco, que tem apresentado um discurso em defesa da diversidade cultural face à globalização. E esse discurso favorece a reafirmação das diferenças étnicas e culturais.

As políticas de patrimônio, sobretudo as relacionadas ao patrimônio dito imaterial, ganham proeminência nesse contexto, juntamente às iniciativas que visam a proteção e a manutenção dos saberes e práticas considerados tradicionais. Dessa forma, o movimento de reafricanização banto, quando começou a se estruturar, encontrou um cenário favorável para apresentar sua agenda e fazer frente à hegemonia nagô, por vezes considerada pelos praticantes do candomblé de tradição banta como uma nagoização ou um iorubacentrismo.

Mas o caminho ainda é longo para que as casas de candomblé de matriz banta obtenham, de fato, o status concedido ao candomblé nagô, considerado o guardião da tradição. Essa ideia foi construída ao longo do século XX, e é ainda hoje reafirmada pelos praticantes e por alguns 
estudos sociológicos e antropológicos. Os praticantes do candomblé nagô contaram com um respaldo advindo do próprio continente africano. Especialmente a partir dos anos 1960, inicia-se um estreitamento de laços religiosos e culturais entre casas de candomblé, consideradas tradicionais na Bahia, e elites oriundas das regiões habitadas por povos iorubás. Esse respaldo não se localizava somente no continente africano, mas também na diáspora, principalmente em Cuba e nos Estados Unidos. Exemplos disso são os Congressos Mundiais da Tradição e Cultura dos Orishas (Comtoc), cuja primeira edição ocorreu em 1981, e o movimento que defende hoje em dia a constituição de uma "religião dos orishas", que juntaria as várias modalidades religiosas que cultuam as divindades de origem iorubá (CAPONE, 1999; 2005).

No caso dos povos chamados "bantos", esse respaldo é ainda frágil, apesar de já haver uma tentativa de articulação capitaneada por Tata Katuvanjesi com o Centro Internacional das Civilizações Bantas (Ciciba $)^{7}$. Essa entidade foi criada em 1983 por iniciativa do então presidente do Gabão, Omar Bongo Ondimba. O Centro foi rapidamente apoiado por outros 10 governantes africanos, pela União Africana e pela Unesco. As relações entre Tata Katuvanjesi e o Ciciba foram se estreitando graças aos Encontros dos Povos Bantos, os Ecobantu.A primeira edição do Ecobantu ocorreu em 2002, na Biblioteca Mario de Andrade, no centro de São Paulo. Em 2004, foi realizado o segundo encontro, na sede do parlamento latino-americano, no anexo do Memorial da América Latina, também em São Paulo. O III Ecobantu aconteceu em 2015, na Galeria Oligo, no centro de São Paulo. Em 2018, o evento retornou para o Memorial da América Latina. Segundo o seu organizador, Tata Katuvanjesi, esse quarto encontro

foi um evento mais fervoroso, com a representação de todos os terreiros angola da Bahia. O Tumba Junsaratava representado pelo Tata Zingê Lumbondo, Esmeraldo Emetério Santana Filho, Xuxuca; Makota Valdina Pinto e várias outras lideranças do Tumba Junsara. O Bate Folha tava representado por Tata Muguanxi, Tata Cícero e uma delegação de Nengwa Kixima; a tradição Angolão Paketan de Mariquinha Lembatava representada por Tata Mutá Imê e Tata Konmannanjy, que é o presidente da Acbantu, a Associação Natural Cultural do Patrimônio Bantu, sediada em Salvador. O Gomeia estava presente. Representações de vários lugares. Teve representação de Palo Mayombe de Cuba e de Argentina. De Angola, veio um grande número. Em torno de 13 pessoas. E tinha também o diretor geral do Ciciba, Dr. Antoine Manda Tchebwa, o Cônsul geral do Gabão, o Cônsul geral de Angola e mais outras representações diplomáticas de outros países africanos. ${ }^{8}$

Do Ecobantu de 2018 nasceu o projeto de lei 10634/2018 que propõe a instituição ao nível federal do dia 13 de outubro como o Dia Nacional das Culturas Bantu9. Durante esse encontro também foi assinado um acordo de cooperação científica e cultural entre o Ilabantu e o Ciciba: 
"Por força desse acordo foi então definido que o Brasil faria parte do Ciciba como convidado e com representatividade daqui para toda América Latina e o Caribe"10. Tata Katuvanjesi foi nomeado representante da diáspora e tomou posse em 2018, em Libreville (Gabão).O projeto comum inclui "a questão da difusão das línguas, dos atos e costumes de um povo transatlântico" ${ }^{11}$.

Vimos que os contatos com a África já iam se fortalecendo desde o fim dos anos 2000. Em 2015, quando esteve em Angola, Tata Katuvanjesi foi recebido tanto por lideranças tradicionais - como o soberano do reino do Bailundo - quanto por lideranças civis - como a então Ministra da Cultura de Angola, Rosa Cruz e Silva. E, em 2019, ele recebeu em seu terreiro a rainha Diambi Kabatusuila do povo lubade BakwaIndu, na região do Kasai, República Democrática do Congo ${ }^{12}$.

Tata Katuvanjesi está, assim, estabelecendo novas rotas transnacionais para fundamentar suas reivindicações de um tradicionalismo banto no Brasil. Essa pode se tornar a base para a construção de um patrimônio cultural comum entre a África e as práticas religiosas do candomblé angola, congo, congo-angola, moxicongo, kassanje, que hoje se afirmambantu, remetendo a um legado cultural africano, certificado pelos estudos antropológicos africanistas. Trata-se, portanto, de um esforço para a construção de um patrimônio afro-diaspórico que quer ocupar a cena pública com a mesma força simbólica de seu antagonista nagô.

\section{MISTURA: VALOR EXCEPCIONAL}

As entidades representativas do candomblé de matriz banta foram fundadas em um período em que era crescente o debate acerca de políticas públicas que visavam a redução das desigualdades raciais e a afirmação da dita diversidade cultural. Diferentes ações foram desenvolvidas nesse sentido, seja no âmbito federal, estadual ou municipal, mobilizando a sociedade civil. Essas entidades tiveram participação em algumas dessas ações, ocasiões em que defendiam pautas comuns do movimento afro-religioso, sendo o combate à intolerância religiosa a principal delas, e também suas pautas específicas, destacando-se a ampliação da representatividade do candomblé de matriz banta, especialmente, no que tange à política patrimonial.

Essa mobilização refletiu, ainda que de forma branda, nas ações desenvolvidas pelo órgão gestor do patrimônio cultural brasileiro. Em 2014, por exemplo, o IPHAN lançou o Prêmio Patrimônio Cultural dos Povos e Comunidades Tradicionais de Matriz Africana em que contemplou projetos culturais apresentados por terreiros vinculados a outras modalidades de culto, que não somente o candomblé nagô (IPHAN, 2016). O objetivo do IPHAN era reconhecer as ações de preservação, valorização e documentação do patrimônio cultural desenvolvidas pe- 
los terreiros. Foram contempladas 31 ações, advindas de terreiros de dez estados brasileiros, incluindo até mesmo terreiros de umbanda. A Bahia foi o estado que foi mais premiado; foram nove propostas. No entanto, já se observava uma certa pulverização dos parcos investimentos do IPHAN em ações voltadas para as religiões afro-brasileiras.

Outra iniciativa que apontava para uma mudança do IPHAN com relação ao patrimônio afro-religioso foi a criação do Grupo de Trabalho Interdepartamental para Preservação do Patrimônio Cultural de Terreiros $(\text { GTIT })^{13}$, em 2013. Esse grupo visava uma atuação direta do órgão do patrimônio na preservação dos bens culturais relativos aos terreiros. Dentre suas ações prioritárias, destacavam-se: a capacitação dos servidores do IPHAN que lidam diretamente com o tema; elaboração de nota técnica para orientação de processos de tombamento e/ou registro; e suporte para conclusão dos processos de tombamento abertos. Buscava-se, dessa forma, uma compreensão da diversidade relacionada às diferentes regiões do território nacional, segundo informado pelo IPHAN (IPHAN, 2015).

Sobre a capacitação dos servidores, vale uma nota. Foram realizados, em 2015, dez encontros com a presença de religiosos afro-brasileiros. Nesses encontros, eram os próprios religiosos que transmitiam as informações sobre a sua modalidade de culto aos técnicos do IPHAN. E estavam representadas diferentes modalidades. Participaram dessa capacitação sacerdotes e sacerdotisas do candomblé nagô, com destaque para o keto, do candomblé jeje e angola, do culto aos Egunguns, do jarê, da jurema sagrada, do xambá, do tambor de mina e do batuque ${ }^{14}$. Esse movimento do órgão patrimonial indicava para uma tentativa de se ampliar o alcance de suas ações, ou melhor, de preservar também outras modalidades que não o já consagrado candomblé nagô. Dessa forma, o IPHAN estaria buscando, em certa medida, se esquivar de um dos problemas decorrentes dos processos de patrimonialização: a cristalização de modelos ideais.

Aliás, esse risco já havia sido enunciado quando do tombamento da Casa Branca. Citando mais uma vez o relator do processo em seu parecer favorável ao tombamento da Casa Branca, Gilberto Velho afirmava que os terreiros, enquanto territórios de uma manifestação religiosa, possuíam um dinamismo próprio. E que as mudanças que viessem a ocorrer nesses espaços não poderiam ser impedidas pelo Estado por conta do tombamento. Ele chamou também atenção para o fato de que o órgão do patrimônio deveria ser flexível diante desse fenômeno religioso, uma vez que a sacralidade "não era sinônimo de imutabilidade", mas tratava-se de um "fenômeno social em permanente processo de mudança” (VELHO, 2006, p. 238).

O alerta de Gilberto Velho, portanto, não impediu que a política patrimonial reificasse um modelo de ortodoxia afro-religiosa: o candomblé de matriz iorubá. Contudo, os bens patrimonializados também têm 
uma história. Eles remetem, de fato, a uma realidade dinâmica, onde os valores dos bens patrimonializados se transformam ao longo do tempo. Como afirmamos anteriormente, a política patrimonial parecia estar "em conserva", pois a visão que orientava os processos de patrimonialização dos terreiros das religiões de matriz africana frisava a preservação da tradição. Mais do que isso: os terreiros tombados eram aqueles que, aos olhos do órgão do patrimônio, haviam preservado, da forma a mais fiel possível, a tradição africana. Seria esse, assim, o "valor excepcional" dos terreiros elevados a patrimônio nacional.

No entanto, um dos últimos terreiros tombados pelo IPHAN indica uma mudança fundamental na forma de entender o que é a "tradição africana" no Brasil. Trata-se do tombamento do terreiro Tumba Junsara. Esse terreiro foi fundado em 1919, em Santo Amaro da Purificação, na Bahia, sendo transferido posteriormente para Salvador, onde encontra-se ainda hoje. No laudo realizado para o processo de tombamento desse terreiro, não foi, de fato, reafirmada a mesma ideia de "tradicionalidade", entendida como fidelidade a um passado africano que, segundo Emerson Giumbelli (2018), estaria na base dos processos de patrimonialização das religiões afro-brasileiras. Pelo contrário, o que foi defendido pela primeira vez foi a ideia da "milonga", ou seja, da mistura.

Por ocasião do tombamento, o presidente da Associação Beneficente de Manutenção e Defesa do Terreiro Tumba Junsara (Abentumba), Esmeraldo Emetério Santana, lembrou que "o valor está na milonga, não na pureza da tradição" ${ }^{15}$. A milonga torna-se assim uma forma de resistência, o "traço de união entre todas as tradições", uma prova viva "do fracasso da política de separação entre os povos africanos escravizados", nas senzalas e nas cidades brasileiras. A força da milonga está então em sua "estratégia criativa", que permitiu ao africano escravizado preservar sua visão de mundo, juntando-a àquelas de seus companheiros de infortúnio.

Diante dessa postura dos detentores do bem cultural alvo de patrimonialização, os representantes do IPHAN se indagavam pela primeira vez: “Como poderia ter pureza?”. A resposta dos defensores do candomblé angola era certeira: "A milonga foi a lei nas senzalas". A suposta falta de "pureza" que levou o candomblé de matriz banta a ser classificado como "degenerado" e, por isso, estigmatizado, ganhava nova intepretação. Com o tombamento do Tumba Junsara, a "mistura" tornou-se, assim, uma marca distintiva e altamente valorizada de uma das mais importantes "nações" do candomblé: a nação angola, a qual vincula-se o referido terreiro.

O tombamento de um bem cultural representa, de fato, uma distinção. E, ao mesmo tempo, discrimina outras práticas culturais que não são consideradas igualmente merecedoras dessa forma de proteção do Estado. Durante mais de 30 anos, o que foi considerado merecedor de proteção foi o legado da tradição nagô, principalmente, e jeje, em certa 
medida: o candomblé nagô com as casas soteropolitanas; o culto dos Egunguns, na Ilha de Itaparica; a Casa das Minas de tradição dahomeana, em São Luís do Maranhão; e ainda o candomblé jeje de Cachoeira, no Recôncavo Baiano.

A única exceção até o tombamento do Tumba Junsara havia sido o reconhecimento concedido pelo IPHAN ao Bate Folha, casa matriz da nação angola-moxicongo em Salvador. Conforme ressalta o relator do processo de tombamento do Bate Folha, o antropólogo Luiz Fernando Dias Duarte,

No conjunto dos terreiros congo-angola existentes na Bahia, o Terreiro do Bate Folha, ou Manso Banduquenqué, é, reconhecidamente, o mais antigo em funcionamento e aquele que logrou preservar de modo mais bem-sucedido seu espaço e suas tradições. É inegavelmente uma referência nacional do rito angola e de sua tradução espacial, bem como uma inestimável fonte de informação sobre as tradições religiosas e línguas trazidas pelo povo banto para o Brasil ${ }^{16}$ (IPHAN, 2003).

Estava, assim, sendo reafirmada a ideia de "tradicionalidade", entendida como fidelidade a um passado africano. Sua inegável "referência nacional do rito angola", como informa o trecho acima, é até mesmo reconhecida por representantes do candomblé nagô. Fato evidenciado em seu processo de tombamento que foi constituído por iniciativa da Sociedade Cruz Santa do Axé Opô Afonjá, e ratificado pela Sociedade Beneficente Santa Bárbara, mantenedora do Bate Folha.

Vale lembrar que a oposição entre práticas religiosas que teriam, mais ou menos, preservado a herança cultural africana tem alimentado, ao longo do século XX, uma hierarquia cultural que fez dos iorubás e dos jejes os defensores da "tradição africana" no Brasil. E, como vimos, isso tem tido um impacto direto nos processos de patrimonailização das religiões afro-brasileiras. Como aponta Giumbelli(2018), um conceito antropológico e "etnicizante" da cultura tem sido aplicado à preservação dessas religiões.

Mas, se na maioria dos casos de tombamento de terreiros o que foi ressaltado foi "a continuidade da civilização africana no Brasil", o caso recente do tombamento do Tumba Junsara ressalta algo bem diferente, ou seja, os processos que permitiram a "formação da cultura afro-americana" no sistema das plantações. Passamos assim de uma ideia de "tradicionalidade", entendida como defesa dos valores ancestrais, a uma tradição que implica não somente a resistência, mas também a adaptação à realidade americana. É da adaptação, da fusão entre as culturas africanas nas senzalas, que nasce a "milonga", valor positivo que descarta a ideia da "pureza" cultural. A própria ideia de África e de seu legado civilizatório no Brasil está assim sendo questionada por esse recente caso de tombamento.

Os casos mencionados neste artigo revelam as disputas existentes no próprio campo afro-religioso, seja entre religiões ou entre modalidades 
de candomblé -especialmente entre as "nações" vinculadas à tradição iorubá e aquelas vinculadas à tradição banta. Como aponta Roger Sansi (2007), nem todos os terreiros são alçados a patrimônio, mas poucos e especialmente aqueles considerados mais tradicionais, mais autênticos e mais históricos. Essa pode ser uma forma de classificação construída a partir de parâmetros externos aos grupos praticantes das religiões afro-brasileiras - no caso por intelectuais, acadêmicos e gestores públicos - mas que encontram, em certa medida, ressonância na maneira como os próprios adeptos buscam também conferir legitimidade à sua prática, vide o movimento de reafricanização tanto de matriz iorubá quanto de matriz banta. Uma maneira que contradiz a própria conformação dessas religiões, que se estabelecem a partir de diferentes matrizes, afros e brasileiras, como defendido no tombamento do terreiro Tumba Junsara.

Ao estabelecermos modelos ideais corremos o risco de confinar as religiões afro-brasileiras a padrões que cerceiam algo que é inerente a elas: sua capacidade de se recriarem, de inventar novos modos de explicar o mundo, de nos conectar com o que está além do ver e do ouvir. Talvez, seja isso que deveria ser explicitado em seus processos de patrimonialização, que tendem a reduzir a experiência humana para construir mecanismos que se adequem à burocracia estatal. Talvez, assim, a patrimonialização poderia ser, de fato, um instrumento de inclusão para fazer valer o direito à diferença, abarcando o candomblé como um afro-patrimônio plural.

\section{NOTAS}

1. Referimo-nos aqui à primeira edição francesa, "Le candomblé de Bahia (rite nagô)", de 1958.

2. Vale lembrar aqui que a oposição entre africanos classificados como bantos e como sudaneses, dentre os quais constam grupos nomeados nagôs, é constitutiva dos estudos afro-brasileiros. Essa oposição, contudo, tem origem nos estudos linguísticos com interesse em diferentes grupos étnicos africanos ainda no século XIX, não restritos, assim, aos desenvolvidos no Brasil.

3. Esses são alguns exemplos de entidades representativas dos praticantes do candomblé de matriz banta. Não se trata, aqui, de uma lista exaustiva.

4. Essa entrevista foi concedida a Stefania Capone. Itaperecica da Serra (SP).

5. Entrevista de Tata Katuvanjesi, concedida a Stefania Capone, em 15 de novembro de 2018. Itapecerica da Serra (SP).

6. Entrevista de Tata Katuvanjesi, concedida a Stefania Capone, em 15 de novembro de 2018. Itapecerica da Serra (SP).

7. Para informações sobre o Ciciba, consultar o site: https://www.cicibabantu.org/.

8. Entrevista de Tata Katuvanjesi, concedida a S. Capone em 15 de novembro de 2018. Itaperecica da Serra (SP).

9. O projeto de lei pode ser acessado no seguinte link: <https://www.camara.leg.br/proposicoesWeb/prop_mostrarintegra?codteor $=1676671 \&$ filename $=P L+10634 / 2018>$. Acesso em: 20 mai. 2020. 
10. Entrevista de Tata Katuvanjesi, concedida a Stefania Capone em 15 de novembro de 2018. Itaperecica da Serra (SP).

11. Entrevista de Tata Katuvanjesi, concedida a Stefania Capone em 15 de novembro de 2018. Itaperecica da Serra (SP).

12. Para outras informações sobre as articulações de Tata Katuvanjesi com o continente africano, consultar o site do seu terreiro: <http://inzotumbansi.org/ home/>.

13. O Grupo de Trabalho Interdepartamental para Preservação do Patrimônio Cultural de Terreiros (GTIT) foi transformado, em 2018, no Grupo de Trabalho Interdepartamental para preservação do patrimônio cultural de Matriz Africana (GTMAF). Essa mudança, conforme consta na Portaria no. 307 do IPHAN, foi realizada com vistas a "ampliação do olhar da instituição para além dos terreiros, englobando os bens culturais relacionados aos povos e comunidades tradicionais de matriz africana" (IPHAN, 2018).

14. As informações sobre o curso de capacitação constam do site do próprio IPHAN. Disponível em: <http://portal.iphan.gov.br/pagina/detalhes/1316/>. Acesso em 20 mai. 2020.

15. Stefania Capone esteve presente à reunião do Conselho Consultivo do Patrimônio Cultural do IPHAN, que declarou o Tumba Junsara patrimônio nacional, em 20 de setembro de 2018, no Forte de Copacabana, Rio de Janeiro. As citações são extraídas das notas tomadas nessa ocasião.

16. Esse trecho, citado pelo relator no dia do tombamento do Bate Folha, é parte do parecer de Márcia Sant’Anna, constante do processo de patrimonialização do referido bem cultural.

\section{REFERÊNCIAS}

BASTIDE, Roger. Les Amériques noires. Lille: Éd. L’Harmattan, 1996 [1967].

BASTIDE, Roger. O candomblé da Bahia: rito nagô. São Paulo: Companhia das Letras, 2001 [1958].

BRASIL. Decreto-lei no 25, de 30 de novembro de 1937. Organiza a proteção do patrimônio histórico e artístico nacional. Diário Oficial da União, Rio de Janeiro, 06 dez. 1937. Disponível em: <http://www.planalto.gov. br/ccivil_03/decreto-lei/Del0025.htm>. Acesso em: 20 mai. 2020.

CAPONE, Stefania. Le pur et le dégénéré: le candomblé de Rio de Janeiro ou les oppositions revisitées. Journal de la Société des Américanistes, Paris, n. 82, p. 259-292, 1996.

CAPONE, Stefania. La Quête de l'Afrique dans le candomblé: pouvoir et tradition au Brésil. Paris: Karthala, 1999.

CAPONE, Stefania. Les Yoruba du Nouveau Monde. Religion, ethnicité et nationalisme noir aux États-Unis. Paris: Karthala, 2005 [Trad. bras. Pallas, 2011].

CAPONE, Stefania. Reafricanization in Afro-Brazilian Religions: Rethinking Religious Syncretism. In: ENGLER, S.; SCHIMDT, B. (Orgs.). The Brill Handbook of Contemporary Religions in Brazil. Leiden: Brill, 2016. p. 473-488. 
CAPONE, Stefania. A busca da África no candomblé. Tradição e poder no Brasil. 2 ed. Rio de Janeiro: Pallas, 2018 [2004].

CAPONE, Stefania; MORAIS, Mariana Ramos de. De la négation à l'affirmation: le processus d'institutionnalisation du patrimoine culturel afro-brésilien. In: CAPONE, Stefania; MORAIS, Mariana Ramos de (Orgs.). Afro-Patrimoines: culture afro-brésilienne et dynamiques patrimoniales. Paris: Lahic/IIAC/EHESS, 2015. p. 98-18. Disponível em: $<$ http://www.iiac.cnrs.fr/article2813.html>. Acesso em: 20 mai. 2020.

CORRÊA, Alexandre Fernandes. A coleção Museu de Magia Negra do Rio de Janeiro: o primeiro patrimônio etnográfico do Brasil. Mneme, Natal, v. 7, n. 18, p. 50-70, out./nov. 2005.

DANTAS, Beatriz Góis. Vovó nagô e papai branco: usos e abusos da África no Brasil. Rio de Janeiro: Graal, 1988.

INSTITUTO DO PATRIMÔNIO HISTÓRICO E ARTÍSTICO NACIONAL - IPHAN. Ata da reunião do Conselho Consultivo do Patrimônio Cultural, realizada no dia 14 de agosto de 2003. Disponível em:

<http://portal.iphan.gov.br/uploads/atas/2003__01__39a_reunio_ordinria_14_de_agosto.pdf $>$. Acesso em: 20 mai. 2020.

INSTITUTO DO PATRIMÔNIO HISTÓRICO E ARTÍSTICO NACIO-

NAL - IPHAN. Programa Nacional do Patrimônio Imaterial: compêndio dos editais de 2005 a 2010. Brasília: IPHAN, 2016.

INSTITUTO DO PATRIMÔNIO HISTÓRICO E ARTÍSTICO NACIONAL - IPHAN. Atuação do GTIT contribui para a preservação das tradições dos Povos de Terreiros. 2015. Disponível em: <http://portal.iphan.gov.br/ $\mathrm{ba/noticias/detalhes/3383/atuacao-do-gtit-contribui-para-a-preserva-}$ cao-das-tradicoes-dos-povos-de-terreiros>. Acesso em: 20 mai. 2020.

INSTITUTO DO PATRIMÔNIO HISTÓRICO E ARTÍSTICO NACIONAL - IPHAN. Portaria no 307, de 30 de julho de 2018. Institui o Grupo de Trabalho Interdepartamental para preservação do patrimônio cultural de Matriz Africana - GTMAF. Diário Oficial da União, Brasília, 13 ago. 2018. Disponível em: <http://www.in.gov.br/materia/-/asset_publisher/ Kujrw0TZC2Mb/content/id/36471233/do1-2018-08-13-portaria-n307-de-30-de-julho-de-2018-36471224>. Acesso em: 20 mai. 2020.

GIUMBELLI, Emerson. When religion is culture: observation about state policies aimed at Afro-Brazilian religions and other Afro-Heritage. Revista Sociologia e Antropologia, v. 8, p. 401-426, 2018.

MAGGIE, Yvonne. Guerra de orixá: um estudo de ritual e conflito. Rio de Janeiro: Jorge Zahar, 2001 [1977].

MORAIS, Mariana Ramos de. Lesreligions afro-brésiliennes en tant que patrimoine: du conflit à l'institutionnalisation. In: CAPONE, Stefania; MORAIS, Mariana Ramos de (Orgs.). Afro-Patrimoines: culture afro-brésilienne et dynamiques patrimoniales. Paris: Lahic/IIAC/EHESS, 2015. p. 98-18. MORAIS, Mariana Ramos de. De religião a cultura, de cultura a religião: travessias afro-religiosas no espaço público. Belo Horizonte: Editora PUC Minas, 2018. 
NASCIMENTO, Abdias do. O quilombismo: documentos de uma militância pan-africanista. Petrópolis: Vozes, 1980.

PREVITALLI, Ivete Miranda. Tradição e traduções. Tese (Doutorado em Ciências Sociais) - Programa de Estudos Pós-Graduados em Ciências Sociais, Pontifícia Universidade Católica de São Paulo, São Paulo, 2012. SANSI, Roger. Fetishes and monuments: Afro-Brazilian art and culture in Bahia. Nova York: Berghahn Books, 2007.

VELHO, Gilberto. Patrimônio, negociação e conflito. Mana, Rio de Janeiro, v. 12, n. 1, p. 237-248, 2006. 